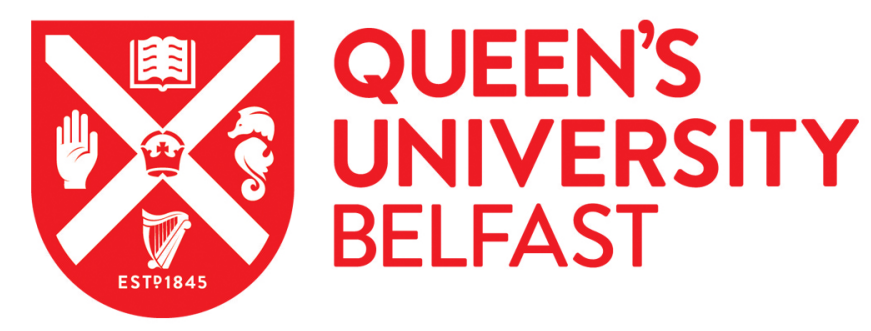

\title{
"Top" or "Bottom" Switches of a Cyclohexanone Monooxygenase Controlling the Enantioselectivity of the Sandwiched Substrate
}

Hu, Y., Wang, J., Cen, Y., Zhang, H., Huang, M., \& Wu, Q. (2019). "Top" or "Bottom" Switches of a Cyclohexanone Monooxygenase Controlling the Enantioselectivity of the Sandwiched Substrate. Chemical Communications, 55(15), 2198-2201. https://doi.org/10.1039/C8CC09951K

Published in:

Chemical Communications

Document Version:

Peer reviewed version

Queen's University Belfast - Research Portal:

Link to publication record in Queen's University Belfast Research Portal

Publisher rights

(c) 2019 The Royal Society of Chemistry. This work is made available online in accordance with the publisher's policies. Please refer to any applicable terms of use of the publisher.

\section{General rights}

Copyright for the publications made accessible via the Queen's University Belfast Research Portal is retained by the author(s) and / or other copyright owners and it is a condition of accessing these publications that users recognise and abide by the legal requirements associated with these rights.

Take down policy

The Research Portal is Queen's institutional repository that provides access to Queen's research output. Every effort has been made to ensure that content in the Research Portal does not infringe any person's rights, or applicable UK laws. If you discover content in the Research Portal that you believe breaches copyright or violates any law, please contact openaccess@qub.ac.uk. 


\section{Journal Name}

\section{COMMUNICATION}

\section{"Top" or "Bottom" Switches of a Cyclohexanone Monooxygenase Controlling the Enantioselectivity of the Sandwiched Substrate}

Received 00th January 20xx, Accepted 00th January 20xx

DOI: $10.1039 / \times 0 \times x 00000 x$

\author{
Yujing Hu, ${ }^{a}$ b Jie Wang, ${ }^{a}$ Yixin Cen, ${ }^{a}$ He Zheng, ${ }^{a}$ Meilan Huang, ${ }^{*}$ b Xianfu Lin, ${ }^{a}$ Qi Wu${ }^{* a}$
}

www.rsc.org/

Single mutation at the switch residues F432 (F432I/L) or $\mathrm{L} 435$ (L435A/G) efficiently reversed the inherent enantiopreference of WT $\mathrm{CHMO}_{\text {Acineto }}$ in the Baeyer-Villiger oxidation of various 4phenyl-cyclohexanone derivatives and 4-alkyl-cyclohexanones, producing a series of substituted lactones with inversed configuration (up to $99 \%$ ee and $99 \%$ conversion).

The tailor-made synthesis of optically pure $(R)$ or $(S)$ lactones are particularly important because many enantiomerically pure lactones are highly valuable intermediates for the production of pharmaceutical drugs ${ }^{1}$ and chiral polyester biomaterials ${ }^{2}$. Hence, development of stereoselective Baeyer-Villiger (BV) reaction catalysts has atrracted great attention. ${ }^{3,4}$ Apart from chiral BV reaction catalysts or reagents developed by chemists, ${ }^{3}$ Baeyer-Villiger monooxygenases (BVMOs) constitute an attractive alternative for the synthesis of enantiopure lactones. ${ }^{4}$ By using BVMOs from different sources, numerous structurally different ketones can be transformed into corresponding products with high ee values. One of the biggest challenges in engineering $\mathrm{BVMOs}$ for tailored $\mathrm{BV}$ reactions is to inverse the enantiopreference of BVMOs because BVMOs are usually highly selective towards one specific configuration of the products.

Cyclohexanone monooxygenase (CHMO) is one of the most studied BVMOs. CHMO from Acinetobacter sp. NCIMB 9871 $\left(\mathrm{CHMO}_{\text {Acineto }}\right),{ }^{5}$ as the most prominent member in the $\mathrm{CHMO}$ family, displayed broad substrate scope for substituted cyclohexanones with relatively high selectivity in comparison to other well-known BVMOs. ${ }^{4}$ Directed evolution of $\mathrm{CHMO}_{\text {Acineto }}$ has been exploited extensively to achieve the desired properties such as thermostability, ${ }^{6}$ regio- $^{7}$ and stereoselectivity $^{8}$, substrate scope, heteroatom oxidation and cofactor usage ${ }^{9}$. So far, only a few studies have been reported

\footnotetext{
a. Department of Chemistry, Zhejiang University, Hangzhou 310027 (China).

E-mail:1lc123@zju.edu.cn,wuqi1000@163.com

b. School of Chemistry and Chemical Engineering, Queen's University, Belfast, BT9

5AG (U.K.). E-mail: m.huang@qub.ac.uk

$\uparrow$ Electronic Supplementary Information (ESI) available. See

DOI: $10.1039 / x 0 x x 00000 x$
}

on reversing the stereoselectivity of $\mathrm{CHMO}_{\text {Acineto. }}$ In the first successful case pioneered by Reetz, ${ }^{8 a}$ a mutant F432S of $\mathrm{CHMO}_{\text {Acineto }}$ was obtained by screening an error-prone polymerase chain reaction (epPCR) library that contained more than 10,000 variants, with reversed stereoselectivity from $9 \%$ ee $(R)$ of WT to $79 \%$ ee $(S)$ in the BV oxidation of 4hydroxycyclohexanone. The F432S mutant showed impressive stereoselectivity for various ketones, ${ }^{8 b}$ however, except for 4hydroxycyclohexanone, the variant only exhibited reversed stereoselectivity for few substrates. ${ }^{8 a}$ Studies on reversing the enantiopreference of other BVMOs, such as cyclopentanone monooxygenase (CPMO) and CHMO from Thermocrispum municipal $\left(\mathrm{CHMO}_{\text {Thermo}}\right)$ have also been reported. ${ }^{10}$ For example, one promising quardraple mutant (LGY3-4-E5:

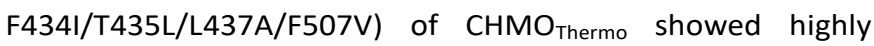
reversed selectivity for the BV oxidation of 4methylcyclohexanone from $99 \%$ ee $(S)$ of WT to $91 \%$ ee $(R)$. However, the reversed selectivity of LGY3-4-E5 mutant toward 4-phenylcyclohexanone was only $30 \%$ ee (+) with the conversion less than $50 \%,{ }^{10 \mathrm{~b}}$ and the limitation also laid in the narrow substrate scope in the attempt to reverse the enantiopreference. To the best of our knowledge, CHMO mutants with highly reversed stereoselectivity for a broad scope of substituted cyclohexanone derivatives, especially for those with large and bulky substituents (Scheme 1), are not yet available.

Screening of large libraries created by conventional directed evolution has been the biggest bottleneck in protein engineering to achieve admired enantioselectivity. ${ }^{11}$ Here we identified two enantioselectivity switches of $\mathrm{CHMO}_{\text {Acineto }}$ at the bottom or the top of the sandwiched substrates, under the guidance of computational simulations. Single mutations at these two switches obtained from a highly focused library completely reversed the enantiopreference in the $\mathrm{BV}$ reactions of various 4-phenyl-cyclohexanone derivatives and 4-alkylcyclohexanones, yielding substituted lactones with high enantioselectivity (up to $99 \% e e$ ). 


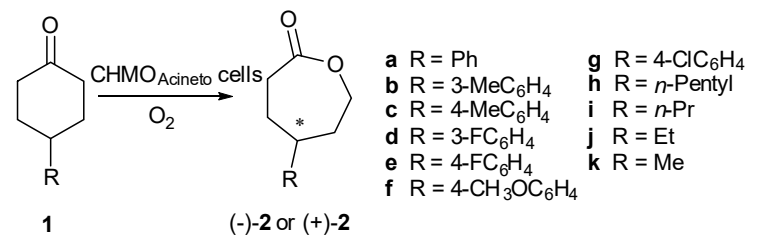

Scheme 1 Biotransformation of various 4-substituted cyclohexanones by $\mathrm{CHMO}_{\text {Acineto }}$

In our study, 4-phenylcyclohexanone (1a) was chosen as a model substrate. Reversing the enantiopreference of $\mathrm{CHMO}_{\text {Acineto }}$ is challenging, since this enzyme is highly selective in the BV oxidation of various substrates (Table S2, ESI + ). ${ }^{8}$ To reduce experimental screening efforts, the rational design of novel $\mathrm{CHMO}_{\text {Acineto }}$ catalysts with reversed enantiopreference was guided by structure-based simulations. The crystal structure of $\mathrm{CHMO}_{\text {Acineto }}$ is not available, so we built a homology model (named as $\mathrm{CHMO}_{\text {homo }}$ ) based on the crystal structure of CHMO from Rhodococcus sp. strain HI-31 (PDB code: 4RG3) ${ }^{12}$, which exhibits high sequence similarity (Fig. S1, ESI + ) around

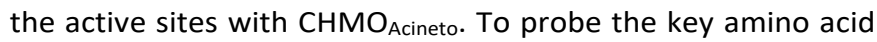
residues that may affect the enzyme's enantioselectivity, molecular docking and 20-ns molecular dynamics (MD) simulation were performed on the WT $\mathrm{CHMO}_{\text {homo }}$ (Fig. 1A, Fig. S4 and Fig. S5A, ESIt). Since the product should be also compatible in the binding pocket of the enzyme and reflect the enantiopreference of the enzyme, product $2 \mathbf{a}$ was used as the model ligand in the simulations. It should be noted that under the catalysis of WT $\mathrm{CHMO}_{\text {Acineto, }}$ the product $\mathbf{2 a}$ with (S)configuration $^{13 a}$ ( $98 \%$ ee $(-)$, entry 1 in Table S2, ESI+) was obtained. Analysis of the binding mode of $\mathbf{2} \mathbf{a}$ in WT disclosed that (S)-2a is stabilized in the binding pocket, and the equatorial phenyl-substituent of ( $S$ )-2a forms a $\pi-\pi$ stacking with the side chain of $\mathrm{F} 432$, contributing to the preference of an equatorial phenyl group (Fig. 1A, Fig. S5A, ESIt). In contrast, (R)-2a could not be docked into the active pocket (Fig. S4B, ESI + ), which is in line with the experimental data (Table S2, ESI ${ }^{\dagger}$ ).

Previous $\mathrm{QM} / \mathrm{MM}$ calculations on the oxygenation of cyclohexanone, 4-methylcyclohexanone ${ }^{14 a}$ and 4hydroxycyclohexanone ${ }^{14 b}$ indicated that the pose of substrates in the binding pocket and the preferred direction of the fragmentation of Criegee intermediate were critical for the enzyme's enantioselectivity (Fig. S2, ESI+). The well-defined position of $\varepsilon$-caprolactone product (Fig. S3, ESIt) in the active sites featuring a certain directionality of the insertion of an oxygen atom was indicated by theoretical investigation ${ }^{14 a}$, which was in line with the crystal pose of $\varepsilon$-caprolactone in the enzyme (PDB code: $4 R G 3)^{12}$. Due to the similarity in the reaction mechanism and optimized geometry, 4-bulky substitutedcyclohexanones were subjected to BV oxidation, similar to unsubstituted cyclohexanone, thus the preferred orientation (equatorial or axial) of their substituent group would ultimately decide the binding mode of the substrates, resulting in different stereoselectivity. Therefore, we propose the residues L143, F432, L435, F505 located above or below the 4-Ph group in $\mathbf{2 a}$ have the potential to affect the enantioselectivity (Fig. 1A).

To make a preliminary assessment of the importance of these

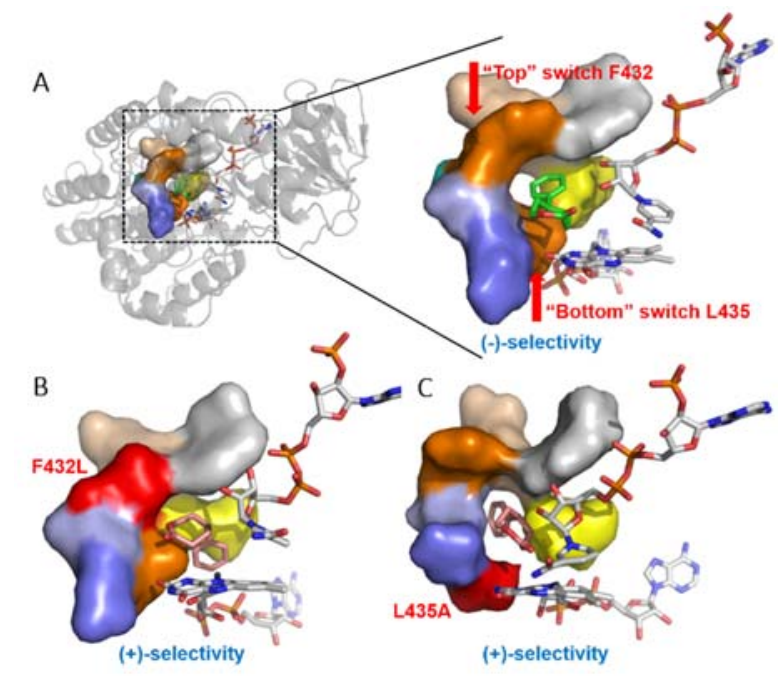

Fig. $1 \mathrm{MD}$ optimized structure of $\mathrm{WT} \mathrm{CHMO}_{\text {homo }}$ in complex with (S)-2a (green) (A), and $\mathrm{CHMO}_{\text {homo }}$ mutant $\mathrm{F} 432 \mathrm{~L}$ in complex with $(R)$-2a (salmon) (B), and $\mathrm{CHMO}_{\text {homo }}$ mutant L435A in complex with ( $R$ )-2a (salmon) (C). WT residues (F432 and L435) are highlighted in orange and the mutated resides ( $L 432$ in B and A435 in C) in red. The other residues are shown in surface: L143-yellow, P431-cyan, T433-lightblue, N434-slate, W490lightgray, F505-wheat. Cofactors (FADHOO and $\mathrm{NADP}^{+}$) are represented by sticks in white.

target residues and reduce the screening efforts, we initially mutated these sites into the amino acids, which have significantly different sizes from the inherent one, and therefore may reshape the binding pocket substantially. Thus the large-sized F432 and F505 residues lining the top binding side of the enzyme were mutated into a very small and medium nonpolar amino acid (Alanine and Leucine); Likewise, the medium-sized leucine at positions 143 and 435 lining the bottom binding side was changed into small alanine and large phenylalanine, respectively. Strikingly, complete reversal in favor of $(R)$-2a (95\% ee (+) in Table 1 and $98 \%$ ee (+) in Table 2) was achieved by F432L and L435A. However, the mutantions at position L143 and F505 did not show any effect on the enantiopreference (Table S3, ESIT). These initial experimental results implied that $\mathrm{F} 432$ and $\mathrm{L} 435$ are essential for the reversal of enantiopreference. Moreover, MD results also showed that the Ph-group of (S)-2a was closer to the residues F432 and L435 than F505 and L143 (Fig. S5A, ESIt). To gain a deep understanding on the effect of the key residues F432 and L435, two saturation mutagenesis libraries at F432 and L435 were constructed and tested.

The mutants F432X were first examined toward ketone 1a. The results revealed that similar to F432L, F432I showed the preference for (R)-2a ( $85 \%$ ee (+), entry 1 in Table 1$)$. However, all other mutants of F432 preserved (S)-enantioselectivity, similar to WT (Table S4, ESI + ). These results indicated that $(R)$ selectivity in the model reaction has strict spacial requirement for the residue at position 432 . When $\mathrm{F} 432$ is changed from G/A, to $\mathrm{V}$, and further to $\mathrm{L} / \mathrm{I}$, the volume of side chains increases accordingly. However, only L/I amino acids are favourable for the $(R)$-configuration enantiomer. Obviously, other mutations with larger side chain than L/I (such as F432Y, F432W, F432P 
Table 1 The mutants F432L and F432I as the catalysts in the desymmetrization of prochiral cyclohexanones $\mathbf{1}^{a}$

\begin{tabular}{|c|c|c|c|c|c|}
\hline \multirow{2}{*}{ Entry } & \multirow{2}{*}{ Substrate } & \multicolumn{2}{|c|}{ F432L } & \multicolumn{2}{|c|}{ F432I } \\
\hline & & Conv. $(\%)^{b}$ & $e e_{p}(\%)^{c}$ & Conv. $(\%)^{b}$ & $e e_{p}(\%)^{c}$ \\
\hline 1 & $1 a$ & 99 & $95(+)$ & 99 & $85(+)$ \\
\hline 2 & $1 b$ & 99 & $95(+)$ & 99 & $95(+)$ \\
\hline 3 & $1 c$ & 99 & $98(+)$ & 99 & $97(+)$ \\
\hline 4 & $1 d$ & 99 & $98(+)$ & 99 & $95(+)$ \\
\hline 5 & $1 e$ & 99 & $99(+)$ & 99 & $92(+)$ \\
\hline 6 & $1 f$ & 99 & $98(+)$ & 99 & $98(+)$ \\
\hline 7 & $1 \mathrm{~g}$ & 99 & $97(+)$ & 99 & $96(+)$ \\
\hline 8 & $1 \mathrm{~h}$ & 99 & $85(+)$ & 99 & $82(+)$ \\
\hline 9 & $1 \mathrm{i}$ & 99 & $77(S)(-)^{d}$ & 99 & $81(S)(-)^{d}$ \\
\hline 10 & $1 \mathrm{j}$ & 99 & $98(S)(-)^{d}$ & 99 & $98(S)(-)^{d}$ \\
\hline 11 & $1 \mathrm{k}$ & 99 & $99(S)(-)^{d}$ & 99 & $99(S)(-)^{d}$ \\
\hline
\end{tabular}

${ }^{a}$ The whole cell experiments are described in Experiment section. ${ }^{b, c}$ Determined by chiral GC. ${ }^{c}$ The data of optical rotation was listed in ESI. ${ }^{d}$ The absolute configuration was confirmed by comparison with the literature ${ }^{13 b}$.

Table 2 The mutants L435A and L435G as the catalysts in the desymmetrization of prochiral cyclohexanones $\mathbf{1}^{a}$

\begin{tabular}{|c|c|c|c|c|c|}
\hline \multirow{2}{*}{ Entry } & \multirow{2}{*}{ Substrate } & \multicolumn{2}{|c|}{ L435A } & \multicolumn{2}{|c|}{ L435G } \\
\hline & & Conv. $(\%)^{b}$ & $e e_{p}(\%)^{c}$ & Conv. $(\%)^{b}$ & $e e_{p}(\%)^{c}$ \\
\hline 1 & $1 a$ & 99 & $98(+)$ & 99 & $99(+)$ \\
\hline 2 & $1 b$ & 92 & $84(+)$ & 95 & $91(+)$ \\
\hline 3 & $1 c$ & 91 & $94(+)$ & 90 & $96(+)$ \\
\hline 4 & $1 d$ & 99 & $99(+)$ & 99 & $99(+)$ \\
\hline 5 & $1 e$ & 99 & $99(+)$ & 99 & $99(+)$ \\
\hline 6 & $1 f$ & 88 & $99(+)$ & 85 & $95(+)$ \\
\hline 7 & $1 \mathrm{~g}$ & 99 & $85(+)$ & 99 & $90(+)$ \\
\hline 8 & $1 \mathrm{~h}$ & 99 & $30(-)$ & 99 & $35(+)$ \\
\hline 9 & $1 \mathbf{i}$ & 99 & $60(R)(+)^{d}$ & 99 & $70(R)(+)^{d}$ \\
\hline 10 & $1 \mathbf{j}$ & 99 & $31(S)(-)^{d}$ & 99 & $28(S)(-)^{d}$ \\
\hline 11 & $1 k$ & 99 & $62(S)(-)^{d}$ & 99 & $70(S)(-)^{d}$ \\
\hline
\end{tabular}

${ }^{a}$ The whole cell experiments are described in Experiment section. ${ }^{b, c}$ Determined by chiral GC. ${ }^{c}$ The data of optical rotation was listed in ESI. ${ }^{d}$ The absolute configuration was confirmed by comparison with the literature ${ }^{13 b}$.

etc.) are not suitable for the reversed selectivity (Table S4, ESI ${ }^{\dagger}$ ). It should be noted that F432S variant does not show reversed preference for 1a, (Table S4, entry 12, ESI+), although it showed reversed stereoselectivity for 4-hydroxycyclohexanone ${ }^{8 a}$.

Further, L435 was mutated into 18 different amino acids, complete reversal in favor of $(R)-2$ a was achieved by $L 435 \mathrm{~A} / \mathrm{G}$ variants with small side chains (entry 1 in Table 2 ). The mutants with side chains longer than leucine displayed low catalytic activity, whereas the rest mutants such as L435C, L435I, L435V and L435T, still preserved the (S)-selectivity (Table S5, ESIT).

Considering the potential application, we further tested the best mutants (F432L and L435A) and WT in a 2-gram-scale conversion of $1 \mathrm{a}$ with a final concentration $12 \mathrm{mM}$ in $1 \mathrm{~L}$ reaction system. The final conversion (95\%-WT, 92\%-F432L, 70\%-L435A) was achieved within $36 \mathrm{~h}$, and the isolation yields are in the range from $51 \%$ to $78 \%$, still maintaining high enantioselectivity (>95\% ee) (Table S6, ESI ${ }^{+}$). The present results demonstate the synthetic utility of these mutants.

To gain insight into the source of notably reversed enantiopreference, molecular simulations were also performed for mutants F432L and L435A (Fig. 1 and Fig. S5, ESI †). Based on the preferred geometry proposed by theoretical investigations ${ }^{14}$, the docked poses of ( $S$ )-2a shown in the active pocket of $\mathrm{F} 432 \mathrm{~L}$ and $\mathrm{L} 435 \mathrm{~A}$ are unproductive because of the unfavorable insertion of oxygen atom (Fig. S4C and S4E, ESI+), while $(R)-\mathbf{2 a}$ is located preferably in the reshaped active pocket (Fig. S4D and S4F, ESIT). Interestingly, MD result in Fig. 1B showed that the mutation $\mathrm{F} 432 \mathrm{~L}$ causes the adjacent loop to undergo a significant conformational change. Accordingly, the side-chain of L432 on the loop is rotated inward the active pocket so that the "top" space of the binding pocket was reduced. As a result, the side-chain of 1432 impeded the potential orientation of the equatorial substituent, thus the unproductive pose (S)-2a with the equatorial substituent rotated $180^{\circ}$ through the main axis (Fig. S4C, ESI ${ }^{+}$). Moreover, the reduced space due to the mutation may fasten the axial substituent of $(R)-2 \mathrm{a}$ in the binding pocket by forming $\mathrm{CH}-\pi$ hydrogen bonds ${ }^{15}$ between the 4-Ph group and the side chain of L143 and L435 (Fig. S5B, ESIT). Similarly, the extra space vacated by mutating $L 435$ into $A$ or $G$ is favourable to accommodate the bulky axial substituent of $(R)-\mathbf{2 a}$, and the hydrophobic cavity environment surrounded by L143 and A435 further stabilizes the phenyl-substituent in axial orientation (Fig. 1C, Fig. S5C, $\mathrm{ESI}+$ ). Therefore, the simulation results account for the reversed enantiopreference of both mutants F432L and L435A at atomic level. When F432 and $\mathrm{L} 435$ are mutated into appropriate residues, these residues lining the top and bottom of the active pocket may serve as a "top" switch and a "bottom" switch, to reverse the enantiopreference of the enzyme for the sandwiched substrates.

Next, the substrate scope of the best single-point mutants (F432L, F432I, L435A, L435G) engineered for substrate 1a was studied. WT enzyme transformed all substrates $\mathbf{1 b} \mathbf{b} \mathbf{- 1} \mathbf{k}$ into the corresponding (-)- or (S)-products with the exception of $\mathbf{1 h}$, for which slight (+)-enantioselectivity is observed (33\% ee) (Table S2, ESI+). Notably, the four aforementioned best mutants catalyzed the BV oxidation of the phenyl-derived cyclohexanones $\mathbf{1 b}-\mathbf{1 g}$, with good yields and highly reversed (+)enantioselectivities (up to $99 \%$ ee, and $99 \%$ conversion) (Table 1,2 ), implying these mutants are indeed excellent catalysts with the capability to reverse the enantiopreference of $\mathrm{CHMO}_{\text {Acineto }}$ with broad substrate scope. For the compounds $\mathbf{1 j}$ and $\mathbf{1 k}$ with short-alkyl substituents, the mutants $\mathrm{F} 432 \mathrm{I}$ and $\mathrm{F} 432 \mathrm{~L}$ provided (S)-lactones with excellent ee, similar to WT (entries 10-11 in Table 1). Interestingly, for all these four mutants, the degree of reversed enantiopreference from (-)- to (+)-configuration toward the alkyl substituted ketones correlates well with the chain length of alkyl substituents. For example, the F432L variant catalyzed the transformation of compounds $\mathbf{1} \mathbf{j} \rightarrow \mathbf{1 i} \rightarrow \mathbf{1} \mathbf{h}$ that have the increased chain length, providing the products with ee values of $98 \%(-) \rightarrow 77 \%(-) \rightarrow 85 \%(+)$ (Table 1, entries 10 , 
9 , 8). L435G variant displays similar features for compounds $\mathbf{1 k} \rightarrow \mathbf{1} \mathbf{j} \rightarrow \mathbf{1} \mathbf{i}(\mathbf{7 0 \%}(-) \rightarrow \mathbf{2 8 \%}(-) \rightarrow 70 \%(+)$, entries $22,21,20$ in Table $2)$. The long alkyl substituent is perferred for (+)-selectivity in BV oxidation reactions catalyzed by these mutants. Except for 4- $n$ propyl substituted cyclohexanone (1i) (Table 2, entry 9), other ketones with short alkyl substitutents at $\mathrm{C}-\mathbf{4}$ position $(\mathbf{1} \mathbf{h}, \mathbf{1} \mathbf{j}$, and 1k), or 2-methyl cyclohexanone (3) and 3-methyl cyclohexanone (6) (Table S7, ESI+) can not be transformed with reversed selectivity, which outlines the limitation of these mutants discussed herein. This is probably because of the mobility of the smaller substrate in the reshaped active site of these mutants. For example, in the case of the "bottom" switch (Fig. 1C, Table 2), the extra space vacated by mutations of $L 435 \mathrm{~A}$ or L435G is favorable for the orientation of the axial substituent, especially for long axial-substituent which may bind more tightly with the reshaped pocket to match the axial space created by the mutation. However, the short substituent of the substrate $(\mathbf{1} \mathbf{j}, \mathbf{1} \mathbf{k})$ may prefer to staying in equatorial rather than in axialdue to lack of potential binding with the enlarged pocket along the axial, such that $(S)$-selectivity would be still preserved.

In conclusion, starting from WT $\mathrm{CHMO}_{\text {Acineto, }}$ we found a "top" or "bottom" switch at position 432 and 435, which can reverse the enantiopreference toward bulky substitutedketones sandwiched between the two switches. By single mutation at either position 432 or 435 , complete reversal of enantiopreference has been achieved. The rational approach combining in silico and experimental studies supersedes the random selection of target residues for mutagenesis, and therefore has drastically reduced the screening effort. Sequences alignment based on the 94 BVMO sequences (Fig. S7, $\mathrm{ESI}+$ ) implied these two switch residues are highly conserved in many BVMO, thus the finding herein will provide a valuable guidance for facile engineering other BVMO with reversed enantiopreference for specific substrates.

This work was supported by National Natural Science Foundation of China (21574113, 21472169) and Zhejiang Provincial Natural Science Foundation (LY19B020014). The authors are also grateful for the computing resource from the high performance computing cluster at Queen's University Belfast.

\section{Conflicts of interest}

There are no conflicts to declare.

\section{Notes and references}

1 D. d. S. Pisoni, J. S. da Costa, D. Gamba, C. L. Petzhold, A. C. d. A. Borges, M. A. Ceschi, P. Lunardi, C. A. S. Goncalves, Eur. J. Med. Chem., 2010, 45, 526-535.

2 (a) S. Shoda, H. Uyama, J. Kadokawa, S. Kimura, S. Kobayashi, Chem. Rev., 2016, 116, 2307-2413; (b) R. Ligny, M. M. Hanninen, S. M. Guillaume, J. F. Carpentier, Chem. Commun., 2018, 54, 8024-8031.

3 (a) M. Uyanik and K. Ishihara, ACS Catal., 2013, 3, 513-520; (b) D. K. Romney, S. M. Colvin, S. J. Miller, J. Am. Chem. Soc., 2014, 136, 14019-14022; (c) P. P. Poudel, K. Arimitsu, K. Yamamoto, Chem. Commun., 2016, 52, 4163-4166; (d) A. Borissov, T. Q. Davies, S. R. Ellis, T. A. Fleming, M. S. W. Richardson, D. J. Dixon, Chem. Soc. Rev., 2016, 45, 54745540 .
4 Select reviews about BVMOs, see: $(a) \mathrm{K}$. Balke, A. Beier, U. T. Bornscheuer, Biotechnol. Adv., 2018, 36, 247-263; (b) J. Dong, E. Fernández-Fueyo, F. Hollmann, C. E. Paul, M. Pesic, S. Schmidt, Y. Wang, S. Younes, W. Zhang, Angew. Chem. Int. Ed., 2018, 57, 9238-9261; (c) Z. G. Zhang, L. P. Parra, M. T. Reetz, Chem. Eur. J., 2012, 18, 10160-10172; (d) H. Leisch, K. Morley, P. C. K. Lau, Chem. Rev., 2011, 111, 4165-4222; (e) D. E. Torres Pazmiño, H. M. Dudek, M. W. Fraaije, Curr. Opin. Chem. Biol., 2010, 14, 138-144; (f) K. Balke, M. Kadow, H. Mallin, S. Sass, U. T. Bornscheuer, Org. Biomol. Chem., 2012, 10, 6249-6265.

5 C. T. Walsh and Y. C. Chen, Angew. Chem., Int. Ed., 1988, 27 333-343.

6 (a) S. Schmidt, M. Genz, K. Balke, U. T. Bornscheuer, J. Biotechnol., 2015, 214, 199-211; (b) H. L. van Beek, H. J. Wijma, L. Fromont, D. B. Janssen, M. W. Fraaije, FEBS Open Bio., 2014, 4, 168-174; (c) D. J. Opperman, M. T. Reetz, ChemBioChem, 2010, 11, 2589-2596.

7 (a) K. Balke, S. Schmidt, M. Genz, U. T. Bornscheuer, ACS Chem. Biol., 2016, 11, 38-43; (b) H. L. van Beek, E. Romero, M. W. Fraaije, ACS Chem. Biol., 2017, 12, 291-299; (c) K. Balke, M. Bäumgen, U. T. Bornscheuer, ChemBioChem, 2017, 18, 1627-1638.

8 (a) M. T. Reetz, B. Brunner, T. Schneider, F. Schulz, C. M. Clouthier, M. M. Kayser, Angew. Chem., Int. Ed., 2004, 43, 4075-4078; (b) M. D. Mihovilovic, F. Rudroff, A. Winninger, T. Schneider, F. Schulz, M. T. Reetz, Org. Lett., 2006, 8, 12211224; (c) Z. G. Zhang, G. D. Roiban, J. P. Acevedo, I. Polyak, M. T. Reetz, Adv. Synth. Catal., 2013, 355, 99-106.

9 (a) M. T. Reetz, F. Daligault, B. Brunner, H. Hinrichs, A. Deege, Angew. Chem., Int. Ed., 2004, 43, 4078-4081; (b) A. Beier, S. Bordewick, M. Genz, S. Schmidt, T.v an den Bergh, C. Peters, H. J. Joosten and U. T. Bornscheuer, ChemBioChem, 2016, 17, 2312-2315.

10 (a) C. M. Clouthier, M. M. Kayser and M. T. Reetz, J. Org. Chem., 2006, 71, 8431-8437; (b) G. Y. Li, M. J. L. J. Fürst, H. R. Mansouri, A. K. Ressmann, A. Ilie, F. Rudroff, M. D. Mihovilovic, M. W. Fraaije and M. T. Reetz, Org. Biomol. Chem., 2017, 15, 9824-9829.

11 Recent reviews of directed evolution: (a) N. J. Turner, Nat. Chem. Biol., 2009, 5, 567-573; (b) C. Jäckel, D. Hilvert, Curr. Opin. Biotechnol., 2010, 21, 753-759; (c) M. T. Reetz, Angew. Chem., Int. Ed., 2011, 50, 138-174; (d) C. A. Denard, H. Ren, H. Zhao, Curr. Opin. Chem. Biol., 2015, 25, 55-64; (e) H. Renata, Z. J. Wang, F. H. Arnold, Angew. Chem., Int. Ed., 2015, 54, 3351-3367; (f) A. S. Bommarius, Annu. Rev. Chem. Biomol. Eng., 2015, 6, 319-345; (g) S. C. Hammer, A. M. Knight, F. H. Arnold, Curr. Opin. Green Sustain. Chem., 2017, 7, 23-30; (h) A. Currin, N. Swainston, P. J. Day, D. B. Kell, Chem. Soc. Rev., 2015, 44, 1172-1239; (i) J. B. Wang, G. Y. Li, M. T. Reetz, Chem. Commun., 2017, 53, 3916-3928; (j) C. Zeymer, D. Hilvert, Annu. Rev. Biochem., 2018, 87, 131-157;

12 B. J. Yachnin, M. B. McEvoy, R. J. D. MacCuish, K. L. Morley, P. C. K. Lau, A. M. Berghuis, ACS Chem. Biol., 2014, 9, 28432851.

13 (a) L. C. Goncalves, D. Kracher, S. Milker, M. J. Fink, F. Rudroff, R. Ludwig, A. S. Bommarius and M. D. Mihovilovic, Adv. Synth. Catal., 2017, 359, 2121-2131; (b) M. J. Taschner, D. J. Black; Q. Z. Chen, Tetrahedron: Asymmetry, 1993, 4, 1387-1390.

14 (a) I. Polyak, M. T. Reetz and W. Thiel, J. Am. Chem. Soc., 2012, 134, 2732-2741; (b) I. Polyak, M. T. Reetz and W. Thiel, J. Phys. Chem. B, 2013, 117, 4993-5001; (c) A. T. P. Carvalho, D. F. A. R. Dourado, T. Skvortsov, M. de Abreu, L. J. Ferguson, D. J. Quinn, T. S. Moody, M. Huang, Phys Chem Chem Phys. 2017, 19, 26851-26861. 
Journal Name

15 M. Nishio, Y. Umezawa, J. Fantini, M. S. Weiss and P.

Chakrabarti, Phys. Chem. Chem. Phys., 2014, 16, 12648-

12683. 
